\title{
Image acquisition effects on Unmanned Air Vehicle snow depth retrievals
}

\author{
Ahmet Emre Tekeli and Senayi Dönmez \\ Civil Engineering Department, Çankırı Karatekin University, Çankırı, 18100, Turkey \\ Correspondence: Ahmet Emre Tekeli (ahmetemretekeli@karatekin.edu.tr)
}

Received: 16 April 2018 - Revised: 20 September 2018 - Accepted: 24 September 2018 - Published: 18 December 2018

\begin{abstract}
Advancements in technology have facilitated new opportunities in aerial photogrammetry; one of these is the use of unmanned aerial vehicles (UAVs) to estimate snow depth (SD). Here, a multi-rotor type UAV is used for SD retrievals over an area of $172000 \mathrm{~m}^{2}$. Photos with $80 \%$ forward and $60 \%$ side overlaps were taken by UAV on two different (snow-covered and snow-free) days. SD estimations were obtained from the difference between 3-D stereo digital surface models (DSMs) produced for both days. Manual SD measurements were performed on the ground concurrent with UAV flights. The current study is unique in that the SD retrievals were derived using two different image acquisition modes. In the first, images were taken as UAV was continuously flying and in the second UAV had small stops and kept its position in air fixed as the photos were taken. Root mean square error of UAV derived SDs is calculated as $2.43 \mathrm{~cm}$ in continuous and $1.79 \mathrm{~cm}$ in fixed acquisitions. The results support the hypothesis, based on theoretical considerations, that fixed-position image acquisitions using multi-rotor platforms should enable more accurate SD estimates. It is further seen that, as SDs increased, the errors in SD calculations are reduced.
\end{abstract}

\section{Introduction}

Accurate estimation of water potential within the basin is important for optimum management of water resources. To this end, timely and accurate measurements of the rainfall and snowfall, which are major fresh water inputs into the basin, are needed. Runoff due to snowmelt is key to meeting the demands for freshwater in many regions (Barnett et al., 2005).

Reliable estimation of snow depth (SD) and snow water equivalent (SWE) which are indicators of water potential of the basin are very important for hydrological modelling, flood forecasting, avalanche mitigation and disaster management (Vander Jagt et al., 2015). SD and SWE measurements have been performed since 1960s using the snow courses. However, generally bi-weekly performed snow courses are not temporally dense enough to monitor changes in snow depth. Snow pillows and depth sensors improve the temporal resolutions of SD and SWE data obtained from the field. Moreover, they provide the most reliable information about SD and SWE. However, they provide point values and can only explain $30 \%$ of the observed spatial variability in SD (Erxleben et al., 2002). Moreover, getting data from moun- tainous regions, where the main snowfall occurs, is limited due to safety and logistics.

Snow covered areas (SCA), by changing from $46.5 \times$ $10^{6} \mathrm{~km}$ in January to $3.8 \times 10^{6} \mathrm{~km}$ in August for Northern Hemisphere (Robinson et al., 1993), show the highest variation on Earth's surface after sea ice (Papa et al., 2002). Remote sensing (RS) provided new opportunities in globally monitoring SCA showing such large variation. Furthermore, RS facilitates the collection of temporally and spatially distributed SCA information while minimizing the risks associated with data acquisition with in-situ methods in high-risk areas (Vander Jagt et al., 2015).

Although methods for SD estimations using aerial photogrammetry have been available since the 1960s, the utility of these methods has been limited due to the high cost and limited accuracy of the SD estimates (Vander Jagt et al., 2015; Nolan et al., 2015). However, due to recent advancements in computer technology including the performance of photogrammetric software, along with improvement in cameras, Global Positioning System (GPS), and Inertial Measurement Units (IMU), there has been a renewed interest in the use of aerial photogrammetry for monitoring snow 


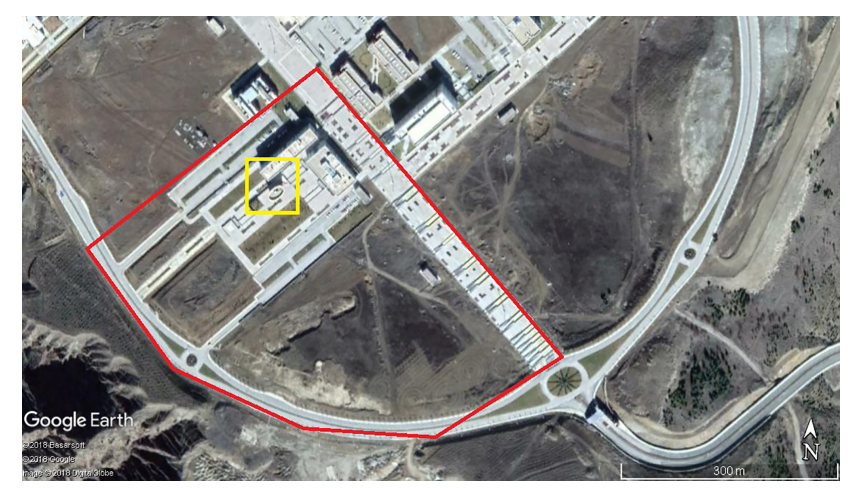

Figure 1. Study area within Uluyazı Campus.

depth. Mounting such equipment onto Unmanned Air Vehicles (UAV) has led to reduced aerial photogrammetry costs which eventually increased the use of UAVs in the field of geosciences (Westoby et al., 2012; Colomina and Molina, 2014). UAVs provided high temporal and spatial resolutions with their rapid image acquisition and low altitude flying capabilities. Moreover, as UAVs became portable, they have been used in cadastral, archeological and vegetation studies (Manyoky et al., 2011; Rinaudo et al., 2012; Zarco-Tejada et al., 2012) and started to take place in many applications of classical RS and aerial photogrammetry.

Investigations into the utility of using UAVs to estimate SD are nascent and prior studies have focused on the use of in-flight imagery from fixed-wing or multi-rotor UAVs (Bühler et al., 2016; Harder et al., 2016; De Michele et al., 2016). In this study, the effects of image acquisition method (UAV in-flight and UAV at fixed position) on UAV based snow depth accuracies are investigated. To the current knowledge of the authors such a comparison is not available in literature yet.

\section{Study Area}

The study area is located in Uluyazı Campus of Çankırı Karatekin University being in $3 \mathrm{~km}$ north-east of Çankırı province $\left(40^{\circ} 37^{\prime} \mathrm{N}, 33^{\circ} 36^{\prime} \mathrm{E}\right)$. Figure 1 shows the study area $\left(172000 \mathrm{~m}^{2}\right)$ in red polygon roughly including Engineering and Science Faculties and the open space to the south. It comes fourth, in terms of areal coverage, after Harder et al. (2016), $320000 \mathrm{~m}^{2}$, De Michele et al. (2016), $300000 \mathrm{~m}^{2}$, Bühler et al. (2016), $275000 \mathrm{~m}^{2}$.

\section{Methodology}

SD estimations using UAV are based on the difference of Digital Surface Models (DSMs) obtained on snow covered and snow-free days (Vander Jagt et al., 2015; Bühler et al., 2016; De Michele et al., 2016; Avanzi et al., 2017). Although some researchers used fixed wing UAVs (De Michele et al.,

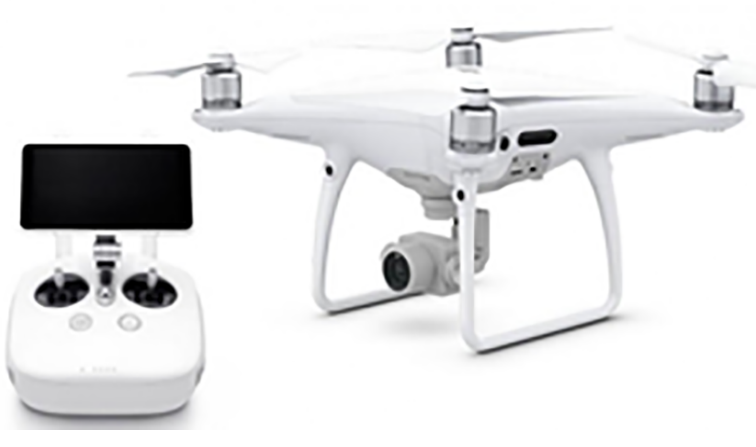

Figure 2. UAV used in the study.

2016; Harder et al., 2016), a multi-rotor UAV, also known as quadcopter or multicopter (Fig. 2), namely DJI Phantom, is used here because of its greater stability (Vander Jagt et al., 2015; Bühler et al., 2016; Avanzi et al., 2017).

To increase the accuracy of the derived DSMs and orthophotos, ground control points (GCPs) distributed as homogeneously as possible over the study area were used following the approach of Vander Jagt et al. (2015), De Michele et al. (2016) and Harder et al. (2016). The location $(x, y, z)$ of GCPs were collected using Leica Viva Global Navigation Satellite Systems (GNSS) receivers.

The flight dates, 3 February and 24 March 2017 for the snow-covered and snow-free cases, respectively, were chosen based on the predicted total cloud cover from the ECMWF numerical weather prediction model. Flight path was arranged to enable $80 \%$ forward and $60 \%$ side overlap and uploaded to UAV before the take-off. Other than take-off and landing phases all flight was performed autonomously. Figure $3 \mathrm{a}$ and $\mathrm{b}$ shows photos from snow-covered and snow-free conditions of the yellow region presented in Fig. 1.

\section{Results and Discussions}

Before SD calculations, the geolocation $(x, y, z)$ accuracies of DSMs were assessed by comparing with GCP measurements performed onsite. They were found to be accurate to within $\pm 2.5 \mathrm{~cm}$; this is similar to the uncertainty of $3 \mathrm{~cm}$ reported by Nolan et al. (2015). Then, orthophotos and DSMs were obtained for snow and snow free days (Fig. 4a and b).

Using the orthophotos and point clouds, DSMs (Fig. 5a and b) were derived. The difference between two DSMs produced SD values. The differences between UAV derived SDs and manual measurements are presented in Fig. 6 for two different image acquisitions (in-flight/at fixed point) on snowy day. Figure 6 shows that the bias in SD calculations decreases as SD values increase. This finding is similar to De Michele et al. (2016) and Avanzi et al. (2017). Although SD was determined for all locations using the imagery collected for UAV in-flight, it was not possible to determine SD in all cases 

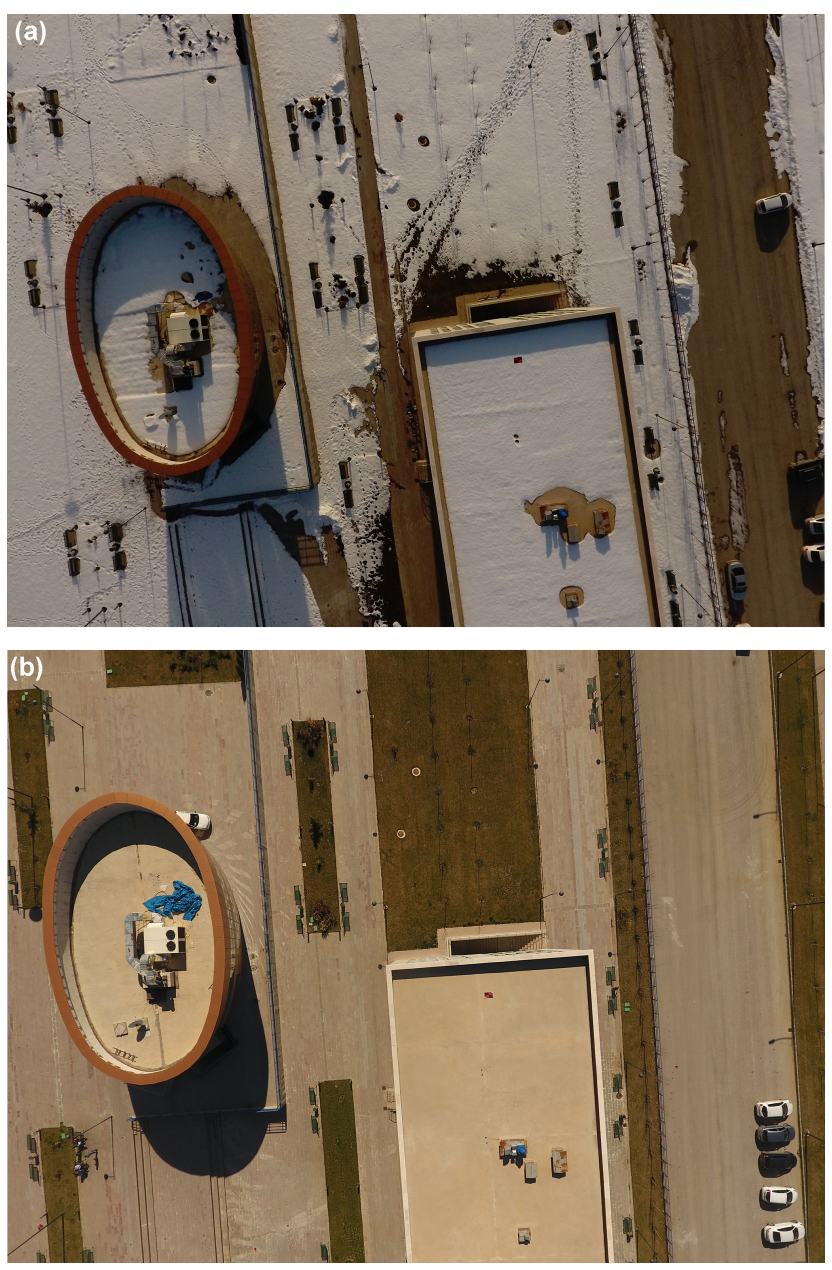

Figure 3. Image for 3 February (a) and 24 March 2017 (b).

when using imagery collected for UAV in fixed-positions due to the insufficient lighting.

Figure 7 shows the bias comparisons for the updated case based on the light conditions.

Scattered diagrams of calculated and measured SDs are presented in Fig. 8 for both in-flight/at fixed point cases.

Figures 7 and 8 indicate that the calculated SDs by fixed point image acquisitions gave smaller biases and higher correlations.

\section{Conclusions}

In this study, SDs derived from UAV images obtained by using two different image acquisition modes were compared. In the first case, the images were acquired while the UAV was in continuous flight mode and in the second case; they were collected while the UAV was kept in a fixed position. The UAV derived SDs were also compared with manual SD measurements performed concurrent with UAV flights over an area of $172000 \mathrm{~m}^{2}$ on the Uluyazı Campus of Çankırı Karatekin University. The locational accuracies DSMs were
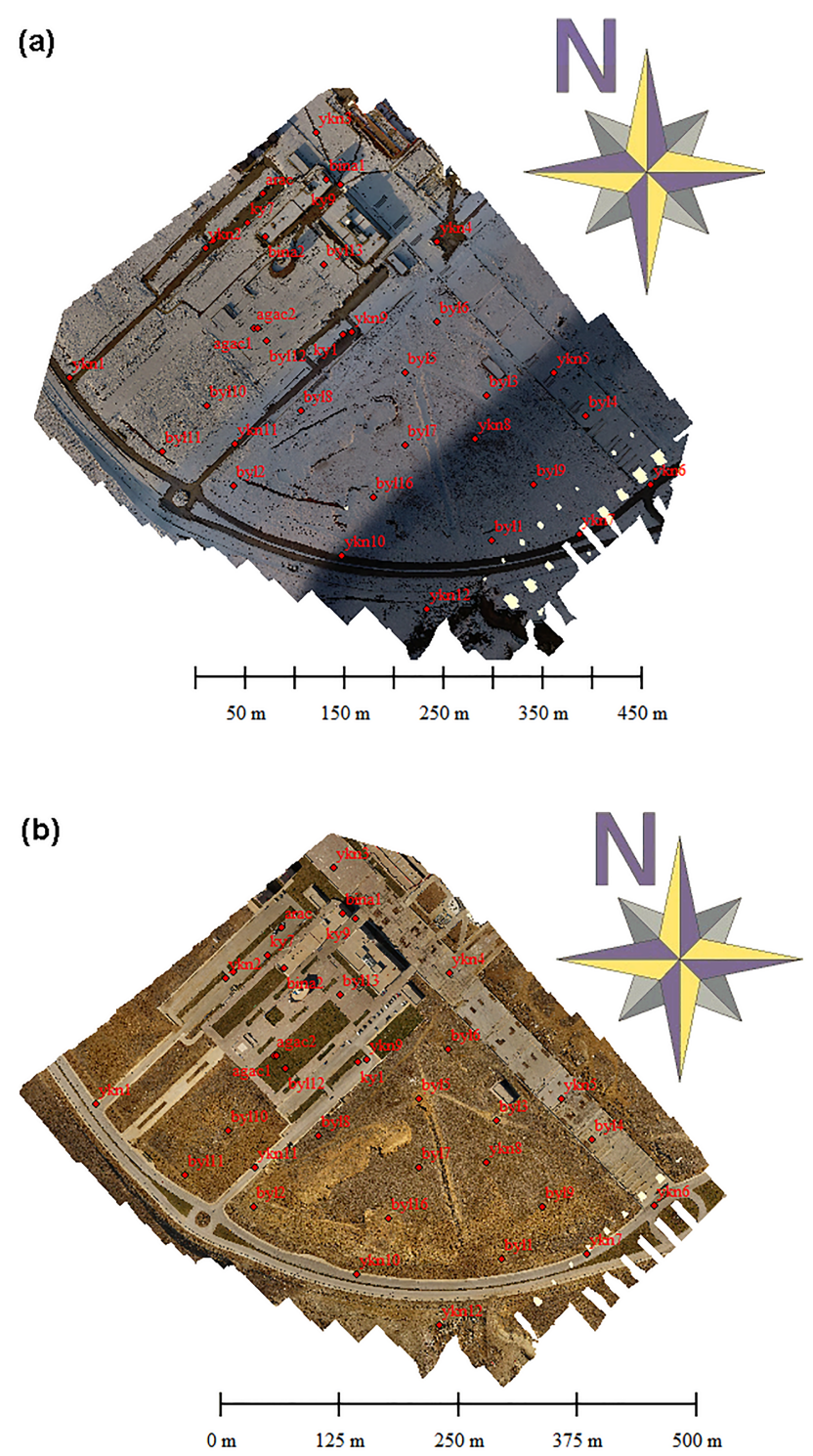

Figure 4. Orthophotos for snow (a) and snow free days (b).

computed using ground control points (GCPs) as $\pm 2.5 \mathrm{~cm}$. The Root Mean Square Error (RMSE) of SD measurements were 2.43 and $1.79 \mathrm{~cm}$, respectively, for in-flight and at fixedposition image acquisitions. The smaller RMSE agrees with the theoretical expectation. Also, the coefficient of determination $\left(R^{2}\right)$ was higher for fixed position image acquisitions. Although the methodology used is the same in all cases, the accuracy of the SD estimates increases as the depth increased from 10.5 to $225 \mathrm{~cm}$.

The same effect of lighting conditions on the accuracy of SD estimates described by Harder et al. (2016) were also observed here. Specifically, insufficient light reduced image contrast which eventually affected the accuracy and utility of SD estimates. This effect was particularly pronounced 
(a)
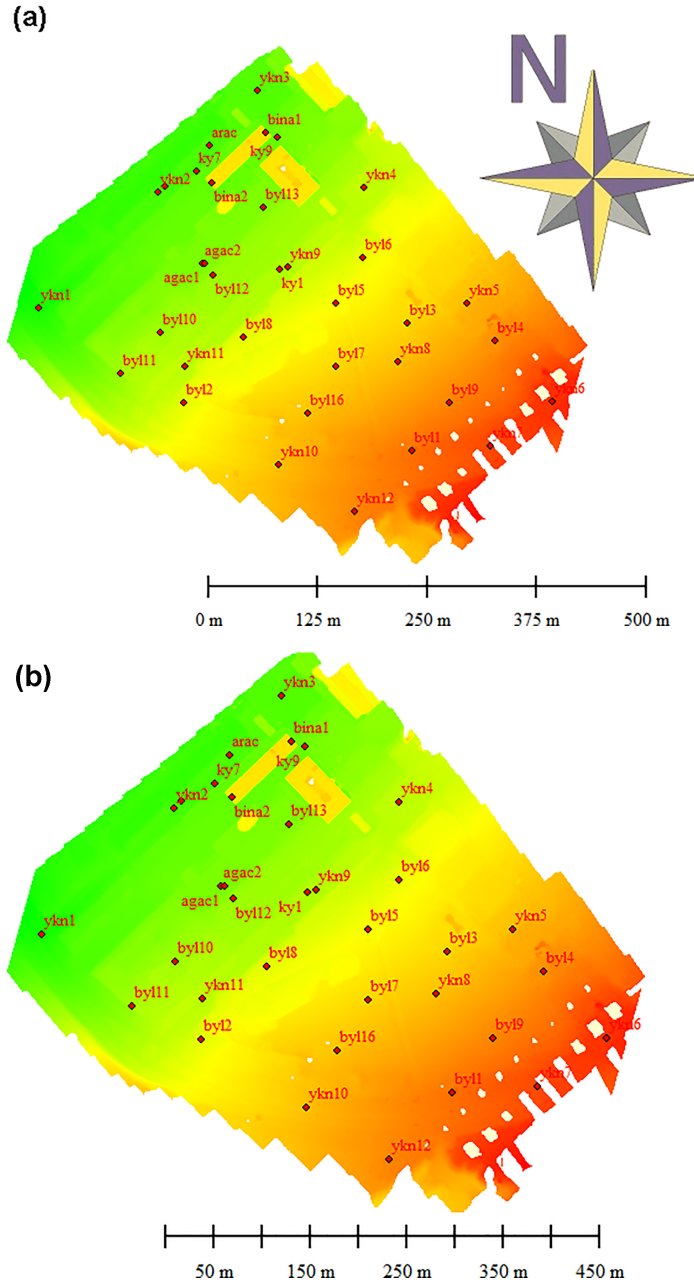

Figure 5. DSMs for snow-covered (a) and snow-free days (b).

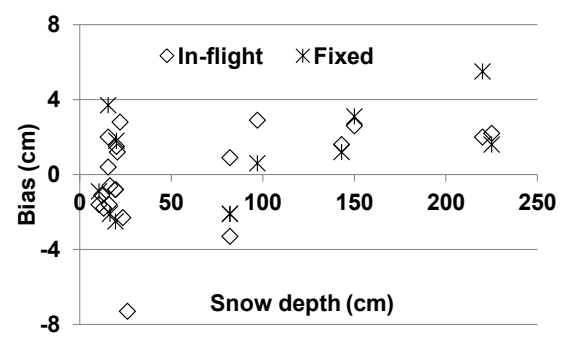

Figure 6. SD bias values for in-flight/at fixed point image acquisitions.

when the approach was applied to imagery collected while the UAV was in fixed-position image acquisition mode.

This work should be followed up by additional studies using near infrared imagery collected via UAV to estimate SD, as also discussed by Bühler et al. (2016).

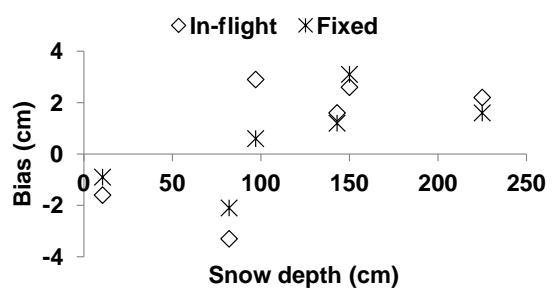

Figure 7. SD bias values for good light conditions.

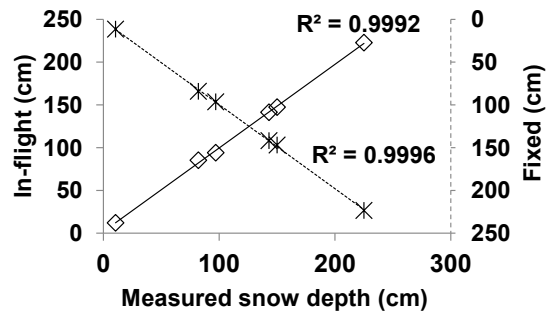

Figure 8. Scatter diagram of SDs.

Data availability. Data are currently not publicly available due to privacy.

Author contributions. AET: Conceptualization, Methodology, Visualization, Writing - Original Draft, Writing - Review \& Editing SD: Funding acquisition, Investigation, Project administration, Writing - Original Draft, Writing - Review \& Editing.

Competing interests. The authors declare that they have no conflict of interest.

Special issue statement. This article is part of the special issue "Earth Observation for Integrated Water and Basin Management: New possibilities and challenges for adaptation to a changing environment". It is a result of The Remote Sensing \& Hydrology Symposium, Cordoba, Spain, 8-10 May 2018.

Acknowledgements. This research was supported by Çankırı Karatekin University BAP project MF-200217B15. The ECMWF numerical weather forecast outputs of total cloud cover were a courtesy of Turkish State Meteorological Services.

Edited by: Michael Cosh

Reviewed by: three anonymous referees

\section{References}

Avanzi, F., Bianchi, A., Cina, A., De Michele, C., Maschio, P., Pagliari, D., Passoni, D., Pinto, L., Piras, M., and Rossi, L.: Measuring the snowpack depth with Unmanned Aerial System photogrammetry: comparison with manual probing and a $3 \mathrm{D}$ 
laser scanning over a sample plot, The Cryosphere Discuss., https://doi.org/10.5194/tc-2017-57, 2017.

Barnett, T. P., Adam, J. C., and Lettenmaier, D. P.: Potential impacts of a warming climate on water availability in snow-dominated regions, Nature, 438, 303-309, 2005

Bühler, Y., Adams, M. S., Bösch, R., and Stoffel, A.: Mapping snow depth in alpine terrain with unmanned aerial systems (UASs): potential and limitations, The Cryosphere, 10, 10751088, https://doi.org/10.5194/tc-10-1075-2016, 2016.

Colomina, I. and Molina, P.: Unmanned aerial systems for photogrammetry and remote sensing: A review, ISPRS J. Photogramm., 92, 79-97, 2014

De Michele, C., Avanzi, F., Passoni, D., Barzaghi, R., Pinto, L., Dosso, P., Ghezzi, A., Gianatti, R., and Della Vedova, G.: Using a fixed-wing UAS to map snow depth distribution: an evaluation at peak accumulation, The Cryosphere, 10, 511-522, https://doi.org/10.5194/tc-10-511-2016, 2016.

Erxleben, J., Elder, K., and Davis, R. M.: Comparison of spatial interpolation methods for estimating snow distribution in the Colorado Rocky Mountains, Hydrol. Process., 16, 3627-3649, 2002.

Harder, P., Schirmer, M., Pomeroy, J., and Helgason, W.: Accuracy of snow depth estimation in mountain and prairie environments by an unmanned aerial vehicle, The Cryosphere, 10, 2559-2571, https://doi.org/10.5194/tc-10-2559-2016, 2016.

Manyoky, M., Theiler, P., Steudler, D., and Eisenbeiss, H.: Unmanned aerial vehicle in cadastral applications, Int. Arch. Photogramm. Remote Sens. Spatial Inf. Sci. XXXVIII-1/C22, 57-62, 2011

Nolan, M., Larsen, C., and Sturm, M.: Mapping snow depth from manned aircraft on landscape scales at centimeter resolution using structure-from-motion photogrammetry, The Cryosphere, 9, 1445-1463, https://doi.org/10.5194/tc-9-1445-2015, 2015.
Papa, F., Legresy, B., Mognard, N. M., Josberger, E. G., and Remy, F.: Estimating terrestrial snow depth with the Topex-Poseidon altimeter and radiometer, IEEE T. Geosci. Remote Sens., 40, 2162 2169, https://doi.org/10.1109/Tgrs.2002.802463, 2002.

Rinaudo, F., Chiabrando, F., Lingua, A., and Spanò, A. T.: Archaeological Site Monitoring: UAV Photogrammetry Can Be An Answer, in: International Archives Of The Photogrammetry, Remote Sensing And Spatial Information Sciences, Vol. XXXIX N. B5, 583-588, ISSN 1682,1750, 2012

Robinson, D. A., Dewey, K. F., and Heim, R. R.: Global snow cover monitoring: an update, B. Am. Meteorol. Soc., 74, 1689-1696, https://doi.org/10.1175/15200477(1993)074<1689:GSCMAU>2.0.CO;2, 1993.

Vander Jagt, V. B., Lucieer, A., Wallace, L., Turner, D., and Durand, M.: Snow Depth Retrieval with UAS Using Photogrammetric Techniques, Geosciences, 5, 264-285, https://doi.org/10.3390/geosciences5030264, 2015.

Westoby, M., Brasington, J., Glasser, N., Hambrey, M., and Reynolds, J.: Structure-from-Motion'photogrammetry: A lowcost, effective tool for geoscience applications, Geomorphology, 179, 300-314, 2012.

Zarco-Tejada, P. J., González-Dugo, V., and Berni, J. A. J.: Fluorescence, temperature and narrow-band indices acquired from a UAV platform for water stress detection using a microhyperspectral imager and a thermal camera, Remote Sens. Environ., 117, 322-337, 2012. 